\title{
Cambios en el paisaje en un valle del oeste catamarqueño durante el Holoceno tardío. Integrando arqueología, palinología y geomorfología
}

\author{
Ana S. Meléndez", Julio J. Kulemeyer ${ }^{* * *}$, Liliana C. Lupo \\ Marcos N. Quesada* y María A. Korstanje
}

Recibido: 31 de marzo de 2017

Aceptado: 14 de julio de 2017

\begin{abstract}
Resumen
El Valle de El Bolsón (Belén, Catamarca) se ubica entre dos áreas geográficas y culturales de gran interés en la arqueología del NOA. Por su ubicación, entre la Puna y los valles bajos, se presenta como un lugar desde donde estudiar los cambios ambientales a nivel local y su relación a las secuencias paleoambientales conocidas en la región. Estudios de polen fósil contenido en la secuencia sedimentaria de Laguna Cotagua informan sobre los cambios en la vegetación a partir de los 5581 años cal AP. El estudio sedimentológico del mismo y de terrazas fluviales con materiales arqueológicos en estratigrafía evidencian abruptos cambios en la geomorfología del valle desde ca. 3000 años AP. El estudio geoarqueológico de los mismos aportó información para ordenar cronológicamente eventos de erosión y deposición de sedimentos que en alguna medida tuvieron impacto en las formas en que las poblaciones prehispánicas habitaron el valle. La finalidad de este trabajo es presentar la integración de estos datos a la información arqueológica disponible y aportar al corpus de datos paleoambientales del NOA.
\end{abstract}

\section{Late Holocene landscape changes in a western Catamarca Valley: integrating archaeology, palinology and geomorphology}

\section{Palabras clave}

Terrazas fluviales Laguna Cotagua Ocupaciones humanas Dinámica geomorfológica Evolución paleoambiental

\footnotetext{
Abstract

The El Bolsón Valley (Belén, Catamarca Province) is located between two geographical and cultural areas of great interest for the region's (Northwest Argentina - NOA) archaeology. Given its location - helmed by the Puna and the lower valleys - it constitutes

* Centro de Investigaciones y Transferencia de Catamarca (CITCa), Universidad Nacional de Catamarca (UNCa) CONICET. Prado 366 (CP K470oBDH). San Fernando del Valle de Catamarca, Catamarca, Argentina. E-mail: solemelendez@gmail.com; mkesada@yahoo.com.ar

** Facultad de Ingeniería, Universidad Nacional de Jujuy (UNJu). Italo Palanca 10 (CP Y460oGNA) San Salvador de Jujuy, Jujuy, Argentina. E-mail: juliojk20oo@yahoo.com.ar

*** Instituto de Ecorregiones Andinas (INECOA), Universidad Nacional de Jujuy (UNJu) - CONICET. Av. Bolivia 1239 (CP Y46ooGNA) San Salvador de Jujuy, Jujuy, Argentina. E-mail: lupoli@imagine.com.ar

**** Instituto Superior de Estudios Sociales (ISES), Facultad de Ciencias Naturales e Instituto Miguel Lillo,

Universidad Nacional de Tucumán (UNT) - CONICET. San Martín 1545 (CP T400oCWE), San Miguel de Tucumán,

Tucumán, Argentina. E-mail: alek@webmail.unt.edu.ar
} 
Keywords

Fluvial terrace Cotagua lagoon Human settlement Geomorphological dynamics Paleoenvironmental evolution an ideal place in which to study environmental changes at a local scale, elucidating its relationship with known paleoenvironmental sequences of the wider NOA region. Studies on fossilized pollen extracted from a Laguna Cotagua sedimentary sequence, identified changes in local vegetation dating to $5581 \pm 40$ years BP. Sedimentology studies of these sequences, as well as others from fluvial terraces containing archaeological material, show abrupt geomorphological changes in the valley from $c a$. 3,000 years BP, onwards. Geoarchaeological studies on these records, contributed data that allowed us to chronologically arrange sediment erosion and deposition events that impacted on the local Prehispanic population's life-ways and settlement of the valley. The aim of this article is to integrate this data, with the available archaeological information, thereby contributing to the corpus of paleoenvironmental data for the NOA region.

\section{Introducción}

El objetivo de este trabajo es conocer los cambios en el ambiente y su relación con las ocupaciones humanas a una escala local, a partir de la integración de diversos análisis para realizar una reconstrucción de los ambientes y el clima del pasado en el contexto del paisaje arqueológico del valle de El Bolsón. Este enfoque incluye el análisis de: a) secuencias de terrazas holocenas, b) mapeos geológico-geomorfológicos, con especial atención a la morfodinámica reciente y c) análisis palinológico de un testigo sedimentario de la Laguna Cotagua.

Los estudios paleoambientales como vías para entender la evolución cultural han crecido considerablemente en el NOA durante los últimos años (Baied y Wheeler, 1993; Kulemeyer, 2005; Kulemeyer y Lupo, 1998, 2006; Kulemeyer et al., 2013; Lupo, 1998; Markgraf, 1985; Olivera, Tchilinguirian y Grana, 2004; Ratto, Montero, Hongn y Valero Garcés, 2013; Schäbitz, Lupo, Kulemeyer y Kulemeyer, 2001; entre otros). La integración de diferentes proxys y escalas de análisis es prioritaria para los contextos culturales en estudios locales, regionales y globales (Flantua et al., 2015). En este sentido, encontramos antecedentes centrados principalmente en la Puna meridional y septentrional (Grana, 2012; Lupo y Echenique, 2001; Lupo, Kulemeyer, Sánchez, Pereira y Cortés, 2016; Olivera et al., 2004; Olivera, Tchilinguirian y De Aguirre, 2006; Oxman, 2015; Oxman, Yacobaccio, Tchilinguirian y Lupo, 2016; Yacobaccio y Morales, 2005, 2011; Yacobaccio et al., 2013) y, más excepcionalmente, en los valles bajos y el sector circumpuneño (Peña Monné y Sampietro Vattuone, 2016; Schittek et al., 2016). Si bien, no vamos a reseñar aquí los alcances de cada una de las investigaciones que preceden, es importante destacar que las mismas parecen haber alcanzado un cierto grado de consenso en cuanto a que las condiciones climáticas durante el Holoceno temprano y medio oscilaron entre periodos de mayor humedad y aridez con puntos de inflexión (ca. 7500-3500 años AP) hasta tornarse similares a las condiciones actuales, ofreciendo así lugares y recursos aptos para ser aprovechados por las poblaciones humanas. Otro acuerdo general es la existencia de condiciones ambientales locales diferenciadas según los procesos generados por los contextos topográficos, tectónicos, geológicos y eventualmente microclimáticos, entre otros, que se deben analizar integrados a los contextos arqueológicos. Bajo estas premisas, abordamos aquí el caso del valle de El Bolsón, un espacio transicional entre los ambientes de valles y Puna catamarqueña (Figura 1). Tal situación implica la existencia de variados microambientes, haciendo que este caso resulte propicio para estudiar, en diferentes escalas de análisis, las relaciones entre los procesos ambientales y culturales sucedidos desde el Holoceno temprano. 


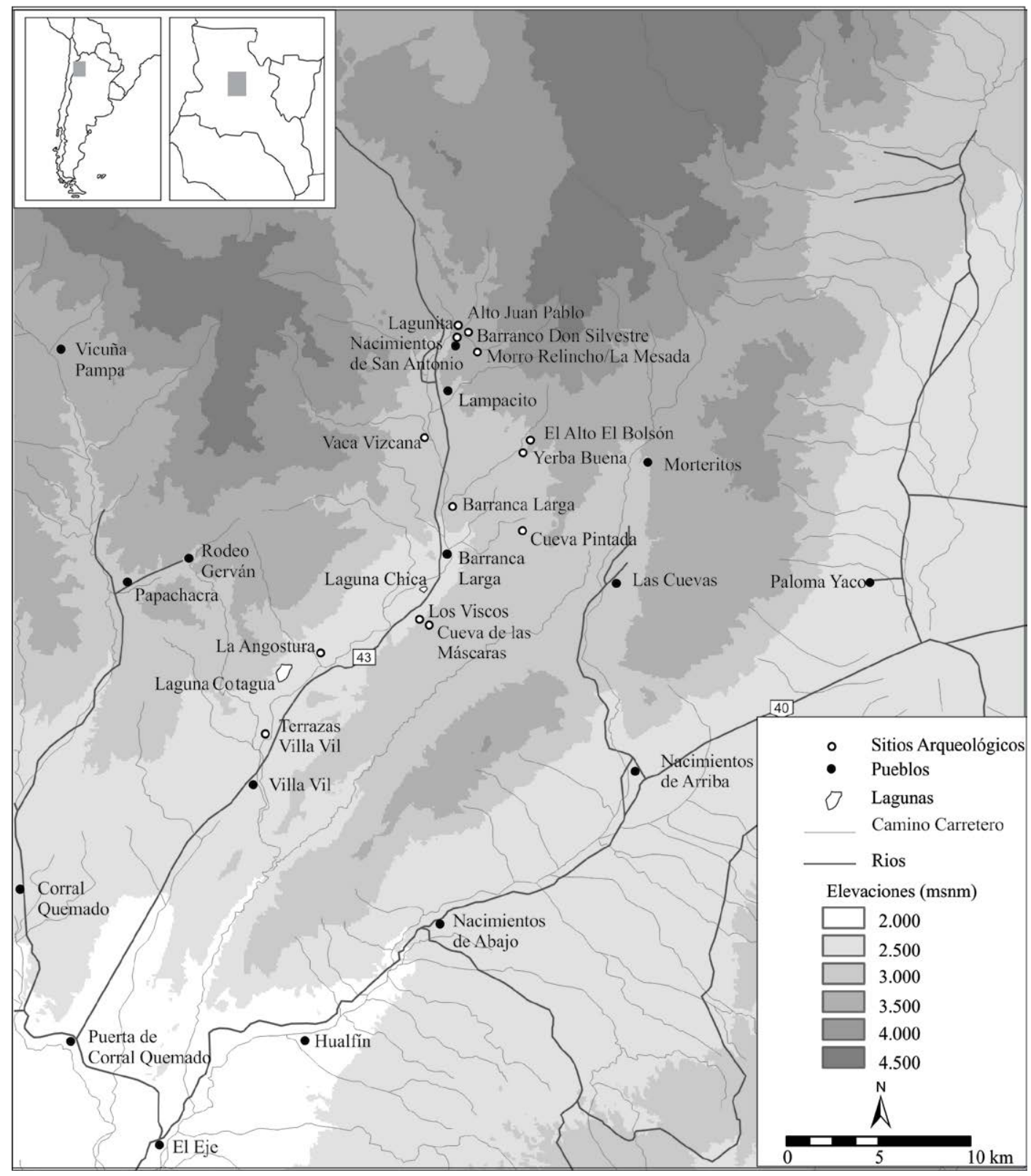

Figura 1. Ubicación del valle de El Bolsón y sitios mencionados en este trabajo.

\section{El área de estudio}

El Valle de El Bolsón está ubicado al oeste de la provincia de Catamarca. Las investigaciones arqueológicas llevadas a cabo allí se centraron en el estudio el paisaje campesino desde tiempos prehispánicos hasta la actualidad, proporcionando un interesante panorama sobre la historia de formación de los paisajes culturales locales. Sin embargo, existe poca información en el área sobre las ocupaciones durante el Holoceno temprano y medio. Algunos hallazgos, como la aparición de una punta cola de pescado en la quebrada de Yerba Buena (Korstanje, 2005) o hallazgos en las quebradas laterales de puntas lanceoladas, asignadas a tipos tecnológicos comunes en el Holoceno medio, insinúan la temprana ocupación del área (Quesada, Moreno y Meléndez, 2013). Las ocupaciones se hacen más visibles a partir del periodo Formativo (ca. 3000 a 1000 años AP): sitios ubicados en el sector norte del valle, como La Mesada, Morro Relincho, 
El Alto El Bolsón y Yerba Buena, dan cuenta del desarrollo de conjuntos aldeanos vinculados a espacios agrícolas. Otros sitios con componentes formativos están ubicados en cuevas y aleros en el sector central del valle, como Cueva Pintada y Alero Los Viscos (Korstanje, 2005). Durante el periodo de Desarrollos Regionales (PDR) (ca. 1000 a 480 años AP) algunas aldeas agrícolas continuaron ocupadas (Quesada y Maloberti, 2015; Quiroga y Korstanje, 2007). En el área aún no se registró información sobre el período Inka ( $c a .480$ a 420 años AP), mientras que el Colonial Temprano (s. XVI y XVII) está apenas representado por el componente Hispano-Indígena de Alero Los Viscos. En alguna medida, como ha señalado Quiroga (2007) es posible que la baja representación del Colonial Temprano se deba a las dificultades que aún existen para reconocer las materialidades de ese período y distinguirlas de momentos anteriores y posteriores. Poco se conocía sobre ocupaciones humanas en los diferentes periodos en los fondos del valle de El Bolsón, hasta los trabajos geoarqueológicos aquí presentados (Korstanje, 2005; Meléndez y Sentinelli, 2017).

\section{Antecedentes de registros paleoambientales en el valle de El Bolsón}

Los primeros registros paleoambientales en El Bolsón fueron obtenidos por Fauqué y Tchilinguirian (2002), quienes estudiaron grandes deslizamientos de laderas al sur del valle, próximos al pueblo de Villa Vil. Estos deslizamientos tendrían una antigüedad de entre 25.000 y 3000 años AP. Si bien el objetivo de ese trabajo era evaluar el riesgo geológico actual sobre la población de Villa Vil, resulta importante para esta investigación que hayan tomado información arqueológica de depósitos fluviales para estimar las cronologías propuestas, marcando un antecedente relevante sobre el estudio de la formación del paisaje en el área y su relación con las ocupaciones humanas en los fondos de valle. Madozzo (2009), por su parte, reconstruyó los ambientes y el clima de los últimos 2.000 años del sector central del valle a partir del análisis de micromamíferos en un abrigo (Cueva de las Máscaras). Tal secuencia, aunque no está vinculada a la información arqueológica, muestra que en ese periodo prevalecieron condiciones generales similares a las actuales, con dos períodos diferenciados, uno de mayor humedad entre 1600 y 1300 años AP y otro de mayor aridez entre 1000 y 600 años AP.

\section{Características ambientales del área}

Como ya se indicó, el valle de El Bolsón se ubica en una posición intermedia entre los ambientes más definidos de Puna y Valles Bajos del NOA, con alturas que van desde los 4.500 m s.n.m. en las sierras de Chango Real al norte hasta los $2.200 \mathrm{~m}$ s.n.m. en la localidad de Villa Vil al sur. Este gradiente altitudinal se traduce en la existencia de una variedad de ambientes distribuidos a lo largo de un valle angosto de $28 \mathrm{~km}$ de longitud. El valle tiene una dirección general norte-sur siguiendo el curso del río homónimo con características climáticas, geológicas, geomorfológicas y de vegetación bien definidas en cada microambiente. El control geológico-estructural lo caracteriza también como un valle asimétrico (Figura 2).

La descripción geológica de la zona realizada por Turner (1973) indica que el área está conformada por un número reducido de formaciones pero con importante presencia (Figura 3). En la cuenca de El Bolsón el basamento está compuesto de rocas metamórficas (esquistos, pizarras y filitas) del Precámbrico, que afloran al norte y oeste y se asignan a la formación Loma Corral. Al este y norte de la cuenca se ubica la formación Chango Real, que es un complejo integrado por sedimentos metamorfizados, con abundante penetración ígnea. Sobre estas formaciones apoya una cubierta sedimentaria cenozoica, denominada grupo El Bolsón, que aflora únicamente en el fondo del valle y presenta materiales clásticos, desde arcillas y limos hasta conglomerados, con una potente intercalación de elementos 


\begin{tabular}{|c|c|c|c|}
\hline $\begin{array}{l}\text { Sierras de } \\
\text { Laguna Blanca }\end{array}$ & $\begin{array}{l}\text { Sierras de } \\
\text { Chango Real }\end{array}$ & $\begin{array}{l}\text { Sierras de } \\
\text { Cajón o de Quilmes }\end{array}$ & $\begin{array}{l}\text { Sierras de } \\
\text { Aconquija }\end{array}$ \\
\hline
\end{tabular}

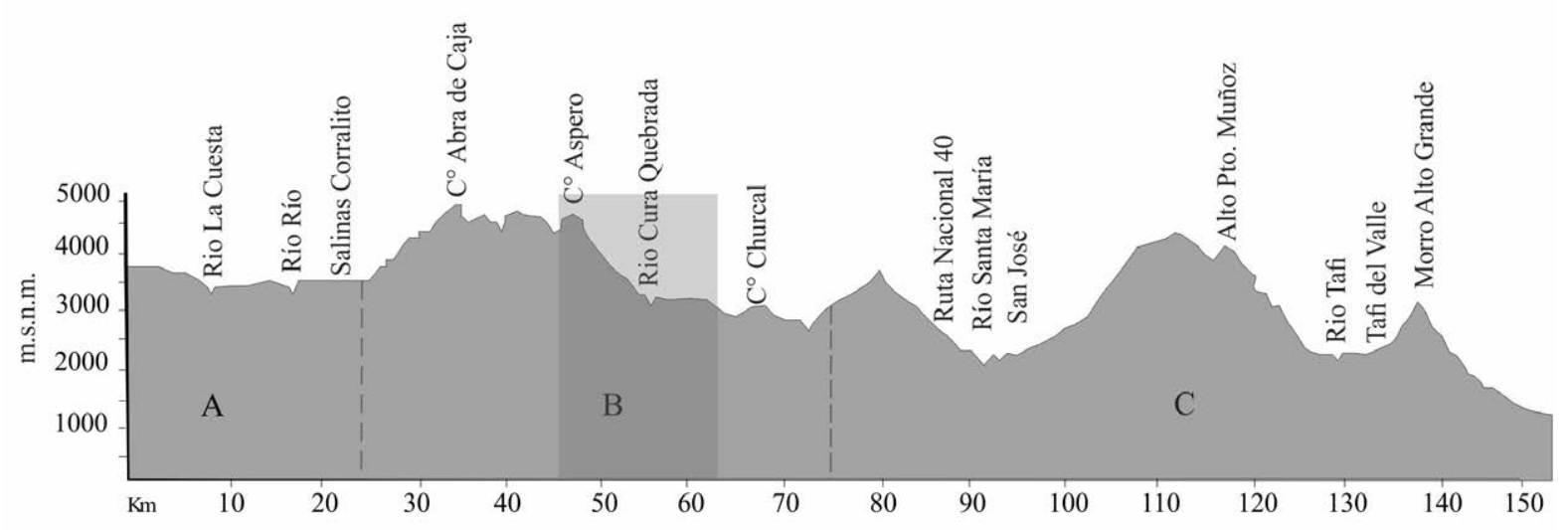

A: Bolsones y cuencas de borde de Puna B: Valles Altos y/o vertientes y cumbres

C: Valles Bajos y/o vertientes y cumbres

Figura 2. Gradiente altitudinal del Valle de El Bolsón. El área de estudio se encuentra resaltada en la imagen (modificado de Korstanje, 2005).

volcánicos en la parte media y, en menor medida, en la parte norte del área, donde predominan las rocas psamíticas. El Cuaternario está representando por materiales de acarreo -depósitos arenosos con intercalaciones arcillosas y numerosas camadas conglomerádicas- dispuestos en niveles aterrazados que se ubican en una franja más o menos estrecha en los márgenes del río El Bolsón. En la Figura 3 se observan, en las márgenes del río El Bolsón, aluviones recientes que corresponden a depósitos del Holoceno generalmente arenosos que constituyen, junto con los abanicos aluviales, los depósitos en los cuales centraremos este trabajo.

La cuenca hidrográfica de El Bolsón se cierra, en el Este, mediante un escarpe estructural atravesado por diferentes cursos de agua paralelos entre sí y de poca extensión. Al Sur, se observan sedimentitas neógenas altamente erosionadas, formando un paisaje de badlands (Kulemeyer et al., 2013). En los fondos de valle se ubican depósitos de acarreos, conformando terrazas y abanicos aluviales asignados al Holoceno. También se encuentran dunas, principalmente en el norte del valle y que evidencian un avance con rumbo noroeste-sudeste. Los suelos y su desarrollo en el área están limitados por la aridez del clima, por lo que son predominantemente arenosos, salinos y pobres en materia orgánica, siendo frecuentes los afloramientos rocosos y pedregosidad (Kulemeyer et al., 2013).

La transición de la Puna a los valles, ubica al área de estudio en un ecotono, en el cual se encuentran las provincias fitogeográficas de Monte, Prepuna y Puna (Cabrera, 1976; Morlans, 1995). Cruz (2012) realizó relevamientos de plantas, censos y mapeos de vegetación y el estudio de lluvia polínica actual, en un gradiente altitudinal entre los 3.200 y los 2.200 m s.n.m. (Figura 4). Ese trabajo involucró muestreos en El Alto El Bolsón, Los Nacimientos de San Antonio, Laguna Chica y Laguna Cotagua, algunos de los cuales incluían sitios arqueológicos estudiados previamente (Cruz, 2012; Korstanje, 2005, 2007). La vegetación de cada provincia está representada según el gradiente altitudinal del valle y las características geológicas y geomorfológicas de cada sector (Cruz, 2012). 


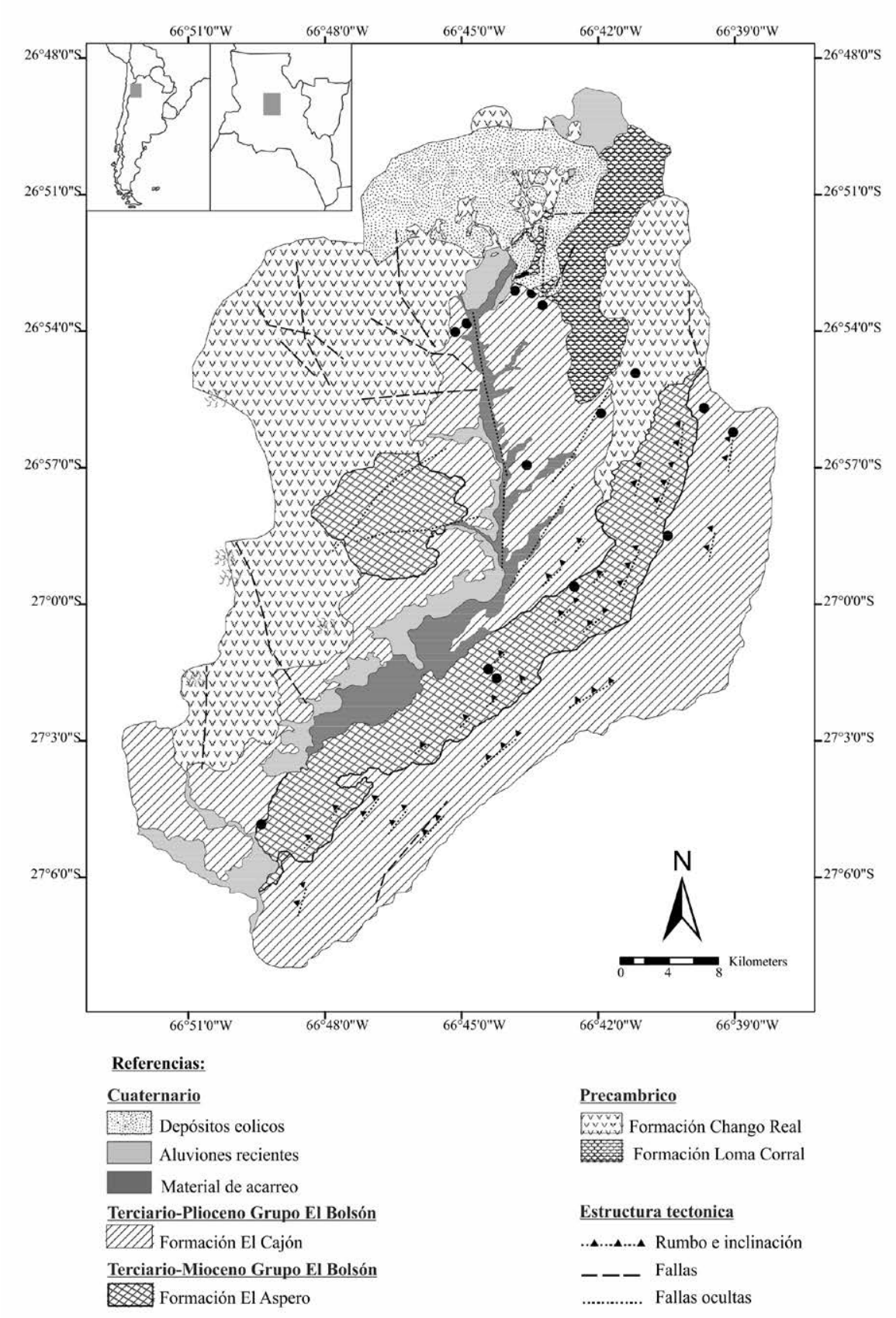

1. En el año 2015 se ha instalado una estación meteorológica en la localidad de Barranca Larga pero aún no hay datos suficientes como para utilizarlos en esta escala de análisis.
Figura 3. Geología del valle de El Bolsón (elaborado a partir de Korstanje, 2005; Kulemeyer et al., 2013; Turner, 1973).

El clima de la zona fue definido como templado de sierras y bolsones. Posee contrastes de temperatura y monto pluvial marcados entre el período estival y el invernal (Irurzun, 1978). En Andalgalá, la estación meteorológica más cercana al área de estudio ${ }^{1}$ (80 $\mathrm{km}$ aproximadamente), predominan los vientos del Noreste y Norte. La temperatura media anual es de $18{ }^{\circ} \mathrm{C}$, variando las máximas medias anuales entre $26^{\circ} \mathrm{C}$ y $27^{\circ} \mathrm{C}$ y las mínimas entre $10^{\circ} \mathrm{C}$ y $12^{\circ} \mathrm{C}$; la amplitud térmica diaria es considerable y alcanza aproximadamente $15^{\circ} \mathrm{C}$. La heliofanía se encuentra entre las más altas del país con $65 \%$ de horas solares efectivas. Las precipitaciones medias se calculan en $200 \mathrm{~mm} /$ año para los valles y bolsones en general, concentradas durante los meses estivales. En los 


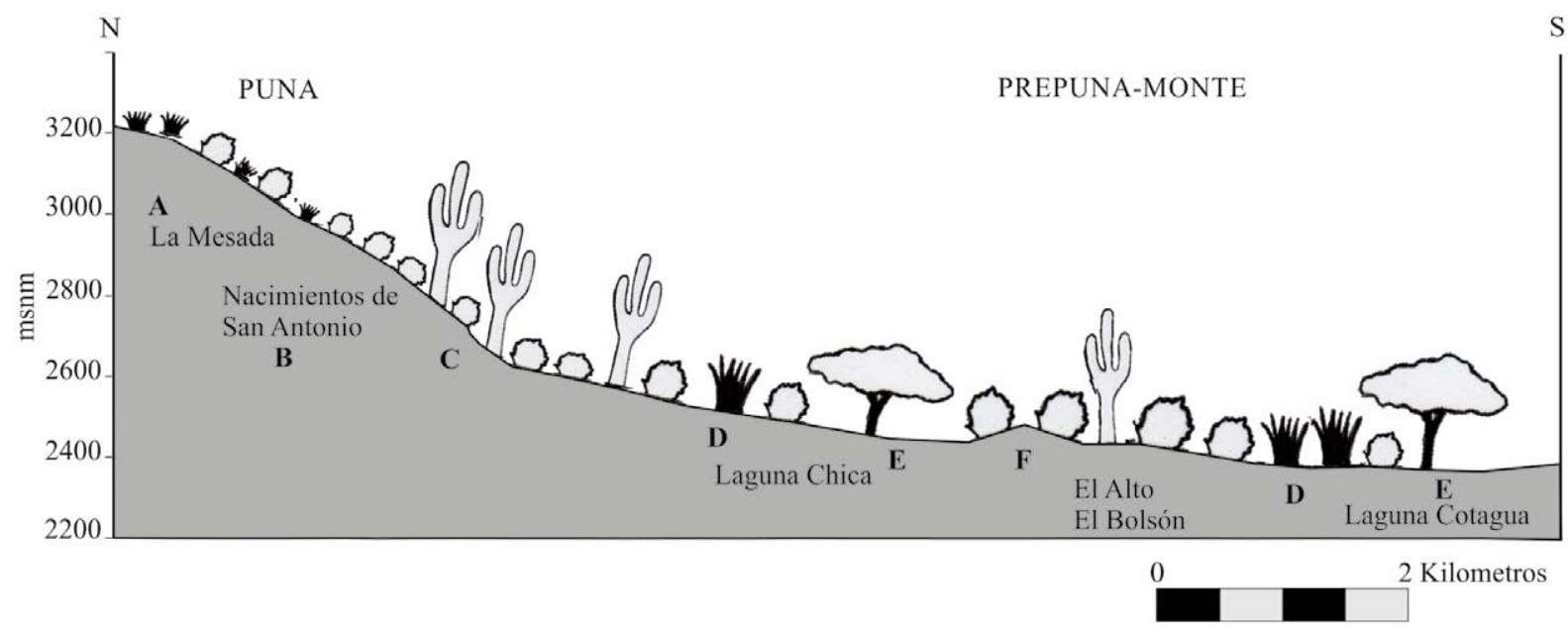

PUNA

A Estepa de Festuca rigescens con Baccharis boliviensis y Parastrephia $s p$

B Estepa arbustiva de Fabiana densa y Ephedra andina
PREPUNA-MONTE

C Laderas con Trichocereus sp.

D Cortaderal de Cotaderia atacamensis

E Bosques de Prosopis sp.

F Matorral de Larrea divaricata y Zuccagnia punctata

Figura 4. Distribución de la vegetación en el valle de El Bolsón (Modificado a partir de Cruz, 2012).

sectores altos de las sierras se produce una mayor condensación y las lluvias pueden alcanzar $450 \mathrm{~mm} /$ año. Ello indica que las zonas más altas son las que más agua de lluvia reciben, según se ha constatado localmente también con registros pluviométricos (Korstanje, 2005). Las heladas se producen entre mayo y septiembre, pero pueden extenderse hasta noviembre.

\section{Materiales y métodos}

$\mathrm{Al}$ tratarse de un punto de encuentro entre dos grandes áreas geológicas-estructurales con características diferenciadas, se optó por un abordaje que implicara dos escalas de análisis. Una de ellas es la regional, a partir de la cual se aborda el valle en relación a otras secuencias paleoambientales conocidas para el NOA. Esto se realizó a partir del análisis de polen fósil, el cual abarca el valle de El Bolsón de manera integral y se vincula a tendencias generales. La otra escala, más localizada y orientada a entender la dinámica de ocupación de sectores particulares del valle, procedió a través del estudio geoarqueológico, geomorfológico y sedimentológico.

\section{Geoarqueología en depósitos de fondo de Valle}

En base al estudio de la carta geológica existente (Turner, 1973) y de imágenes satelitales $\left(\right.$ Google Earth ${ }^{\circ}$ ) se seleccionaron zonas potenciales de trabajo en diferentes sectores del valle (norte, centro y sur). En cada sector se realizaron prospecciones geoarqueológicas sistemáticas intensivas, identificando las particularidades morfocronológicas y arqueológicas, registrando principalmente las geoformas y los eventos de erosióndeposición asignados temporalmente al Holoceno. Para este reconocimiento se definieron transectas siguiendo los márgenes del río El Bolsón en el fondo de valle y 
en las vegas de altura (por debajo de los $3.800 \mathrm{~m}$ s.n.m.) de las quebradas subsidiarias. Estos reconocimientos realizados sobre el terreno y su relevamiento fotográfico permitieron identificar sectores de interés para estudiar con mayor detalle la dinámica sedimentaria en relación a las ocupaciones humanas. Los relevamientos estuvieron basados en las características geológicas, topográficas, geomorfológicas y arqueológicas presentes en estos sectores de interés (Meléndez, 2015). En este trabajo se presentan los registros de las terrazas fluviales de la cuenca inferior del río El Bolsón, próximas al pueblo de Villa Vil, a $8 \mathrm{~km}$ al sur de Laguna Cotagua, donde se relevaron siete perfiles sedimentarios designados con los nombres de Villa Vil Perfil 001 a 007 (en adelante VVP 001 a 007). En cuatro de estos perfiles se tomaron muestras sedimentarias de techo a base cada $10 \mathrm{~cm}$ para la realización de análisis texturales, de materia orgánica y fechados radiocarbónicos: VVP 001 (5,62 m de potencia expuesta), VVP 002 (6,65 $\mathrm{m}$ de potencia expuesta), VVP004 (1,59 $\mathrm{m}$ de potencia expuesta) y VVP005 (2,85 m de potencia expuesta). Se registraron también específicamente los niveles con restos culturales en otros cuatro perfiles los cuales, además, fueron datados por radiocarbono (VVP006, VVP007, VVP008 y VVP009). En el perfil VVP001 se realizaron análisis texturales, tomando como parámetro las unidades sedimentarias reconocidas durante el relevamiento, sin sobrepasar intervalos de $45 \mathrm{~cm}$. Los sedimentos fueron tamizados por vía húmeda (fracción arena) y por pipeteado (limo y arcilla) con mallas de $0,30,0,200$ y $0,063 \mathrm{~mm}$ para las fracciones gruesa, media y fina, respectivamente. La clasificación de los resultados se efectuó siguiendo los criterios de USDA (United States Departament of Agriculture). El criterio de selección de este perfil está vinculado a que éste posee tres fechas radiocarbónicas a diferentes profundidades (base, techo y niveles estratigráficos con restos arqueológicos). Por razones de espacio, este será el único perfil descripto en el apartado de resultados, debido a que su secuencia sedimentaria es comparable y representativa de lo observado en todo el sector de terrazas.

\section{Paleoecología del Testigo Laguna Cotagua}

Para el estudio paleoecológico se trabajó con un testigo sedimentario extraído de Laguna Cotagua en 2010. Esta laguna es un cuerpo de agua temporario de $0,4 \mathrm{~km}^{2} \mathrm{de}$ extensión, ubicado en el sector central del valle al límite oeste del piedemonte y tres de sus flancos se encuentran delimitados por laderas escarpadas de areniscas en franco proceso de erosión con deslizamientos activos (Korstanje, 2005). En el centro de esta laguna se efectuó una perforación de 9 metros de profundidad empleando una sonda y percutor con motor Wacker de dos tiempos. Sobre el testigo de Laguna Cotagua (TLC) se realizaron descripciones sedimentológicas. Posteriormente, se obtuvieron tres muestras de sedimentos orgánicos para datar en diferentes profundidades y se seleccionaron 44 muestras del testigo para el análisis polínico. Este análisis fue completado con tres muestras adicionales que fueron analizadas previamente por Cruz (2012).

Para el aislamiento de polen fósil se siguieron técnicas estándares propuestas para los sedimentos cuaternarios (Faegri e Iversen, 1989; Gray, 1965) bajo un mismo protocolo: determinación del volumen de la muestra, incorporación de dos tabletas de Lycopodium como marcador foráneo, tratamiento con $\mathrm{KOH}$, eliminación de arena con $\mathrm{HF}$, filtrado, acetólisis de Erdtman (1960), diversos lavados con agua destilada y montaje con agua glicerinada. La cuantificación se realizó bajo microscopio óptico con aumentos de 40X, contando un mínimo de 200 granos de polen por preparado. La determinación sistemática de los tipos polínicos se realizó mediante la confrontación con la Palinoteca de referencia (PAL JUA) realizada específicamente para el área (Cruz, 2012) y la bibliografía existente para la región en general (Faegri e Iversen, 1989; Heusser, 1971; Markgraf y D’Antoni, 1978). Las agrupaciones polínicas fósiles fueron establecidas de acuerdo a los criterios ecológicos propuestos por Cruz (2012) para el área estudiada. Los datos obtenidos se presentan en un diagrama polínico en porcentajes, sobre el cual 
se realizó el trazado y la zonación basados en un Análisis de Cluster realizado con el software Tilia 2.0.2 (Grimm, 2004). Todas las fechas radiocarbónicas mencionadas en este trabajo se encuentran detalladas en la Tabla 1 del apartado Resultados. Cinco muestras de sedimento fueron datadas por AMS y siete por radiocarbono convencional (LSC), todas ellas fueron calibradas utilizando el programa en línea OxCal 4.2.3 (Bronk Ramsey, 2009) con la curva de calibración SHCal13 (Hogg et al., 2013). En el caso del testigo Laguna Cotagua se realizó una interpolación lineal de sus fechas ya calibradas mediante el programa Tilia 2.0.41.

\section{Resultados}

\section{Geoarqueología}

Las prospecciones geoarqueológicas en las márgenes del río El Bolsón mostraron que los sectores norte, centro y sur presentan tendencias similares respecto de la formación de los depósitos recientes. Por otro lado, en el sector sur los perfiles expuestos en Villa Vil muestran niveles estratigráficos con abundante material arqueológico e incluso con algunas estructuras arqueológicas descubiertas por la acción erosiva (Figura 5).

Se relevaron un total de seis niveles arqueológicos datados por radiocarbono, los que proporcionaron edades entre 2187 años cal AP (VVP006) y 734 años cal AP (VVP009) (Tabla1). En todos los casos el material fechado es carbón vegetal. Estos depósitos contenían, además, abundante material arqueológico. Se trata de lentes cenicientos con abundantes inclusiones de ítems líticos $(n=32)$, óseos $(n=21)$ en ocasiones calcinados y fragmentos cerámicos $(\mathrm{n}=407)$ coincidentes en estilo, técnica de manufactura y cronología con las fechas obtenidas. En VVP007 se registraron, además, algunos bloques de piedra de módulos de tamaño similares a los empleados como material de construcción de otros sitios mejor conservados del valle. La cerámica corresponde a estilos característicos de distintos momentos del periodo Formativo (3000 a 1000 años AP). Además, en el techo de las terrazas se recuperaron fragmentos cerámicos estilísticamente correspondientes al periodo de Desarrollos Regionales (ca. 1000 a 500 años AP). El análisis tafonómico (Meléndez y Sentinelli, 2017) informa que el conjunto cerámico, lítico y óseo muestra un bajo grado de erosión. En los fondos de las cárcavas se registraron algunos morteros elaborados sobre pesados bloques de piedra. En la Figura 6 pueden observarse algunos de los materiales recuperados en el perfil VVP001. Los niveles arqueológicos de las terrazas de Villa Vil son considerados como contextos de gran integridad. El hallazgo de abundantes fragmentos de carbón, material de baja resistencia mecánica y el bajo grado de erosión que muestran los materiales cerámicos, líticos y óseos incluidos en los conjuntos recuperados permiten afirmar que se trata de depósitos primarios y no del resultado de transporte y redepositación.

Todos los perfiles muestreados en las terrazas de Villa Vil muestran las mismas características litológicas. Por ello, los resultados obtenidos de los análisis texturales realizados sobre el perfil VVP001 pueden ser considerados representativos de la estratigrafía. Este perfil cuenta con el fechado de un nivel cercano a la base (2593 años cal AP) y otro en el techo de la terraza (1237 años cal AP). Con 5,63 m este perfil es el de mayor potencia de sedimentos expuestos y posee una secuencia estratigráfica representativa, sin registro de eventos de erosión o alteraciones aparentes en la depositación de los sedimentos. Está formado por una sucesión de materiales clásticos finos (arenas, limos y arcillas) cuyos porcentajes varían a lo largo de la secuencia. Los niveles con arena gruesa son bajos en casi todo el perfil, excepto entre 3,35 m y 4,35 $\mathrm{m}$ por debajo de la superficie de la terraza, donde alcanzan entre el 15 y el $32 \%$. Tal incremento de arenas gruesas, medias y finas en detrimento de los limos, puede estar indicando una variación en la velocidad de la corriente del río El Bolsón cuando el 


\begin{tabular}{|c|c|c|c|c|c|c|}
\hline Método & $\begin{array}{c}\text { Código de } \\
\text { Laboratorio }\end{array}$ & $\begin{array}{c}\text { Perfil, muestra } \\
\text { (Profundidad en } \\
\text { (cm) }\end{array}$ & Material & $\begin{array}{c}\text { Edad }{ }^{14} \text { C años } \\
\text { AP }\end{array}$ & $\begin{array}{c}{ }^{13} \text { C \% } \\
\text { oo }\end{array}$ & $\begin{array}{c}\text { Probabilidad rango } 2 \\
\text { calibrado } \\
\text { (años cal AP) }\end{array}$ \\
\hline AMS & LTL4411A & TLC-870 & Sedimento orgánico & $5581 \pm 40$ & $29,6 \pm, 6$ & $6438-6296$ \\
AMS & 15 OS/0669 & VVP1-545 & Sedimento orgánico & $2470 \pm 34$ & $-22,2$ & $2717-2380$ \\
LSC & LP-3179 & VVP6-500 & Carbón vegetal & $2230 \pm 80$ & - & $2348-2008$ \\
LSC & LP-3168 & VVP7-400 & Sedimento orgánico & $1860 \pm 100$ & - & $1940-1534$ \\
LSC & LP-3171 & VVP7.1-415 & Carbón vegetal & $1840 \pm 80$ & - & $1930-1528$ \\
LSC & $16 C / 1065$ & VVP4-300 & Carbón vegetal & $1520 \pm 30$ & - & $1413-1307$ \\
AMS & AA89447 & TLC-590 & Sedimento orgánico & $1420 \pm 58$ & $-24,0$ & $1516-1188$ \\
AMS & $15 O S / 0668$ & VVP1-65 & Sedimento orgánico & $1320 \pm 30$ & $-24,2$ & $1279-1161$ \\
LSC & $16 C / 1064$ & VVP1-325 & Carbón vegetal & $1310 \pm 30$ & - & $1274-1191$ \\
LSC & AA88344 & VVPoo8-400 & Carbón vegetal & $1111 \pm 34$ & - & $1001-924$ \\
LSC & AA88343 & VVPoo9-500 & Carbón vegetal & $818 \pm 36$ & - & $749-6760$ \\
AMS & AA89446 & TLC16 & Sedimento orgánico & $345 \pm 67$ & $-23,3$ & $505-300$ \\
\hline
\end{tabular}

Tabla 1. Fechas radiocarbónicas mencionadas en este trabajo.
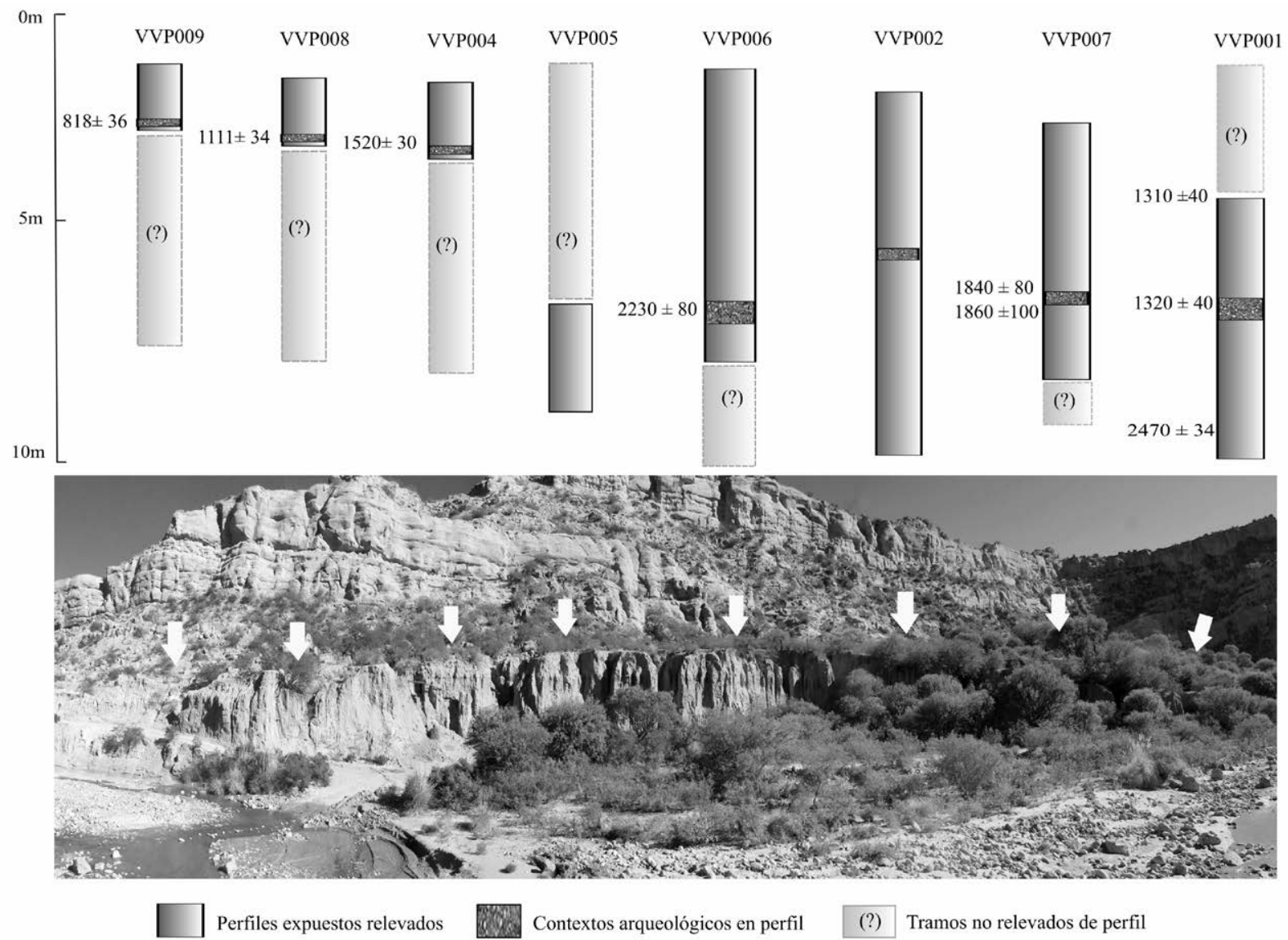

Figura 5. Terrazas fluviales del río El Bolsón, próximas a Villa Vil. 

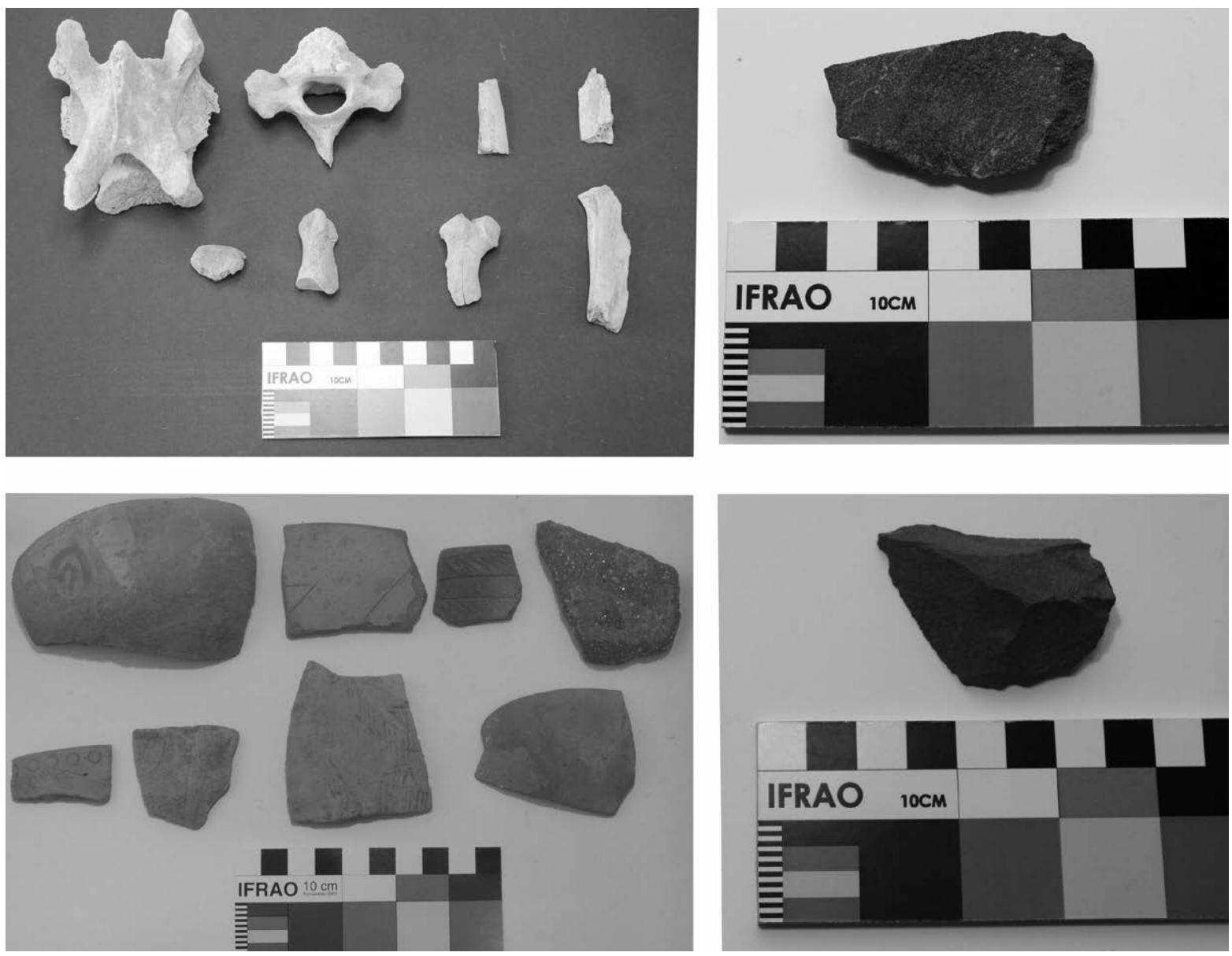

Figura 6. Material arqueológico en estratigrafía procedente del perfil VPoo1.

depósito aún se encontraba en formación. La escasa presencia de rodados y bloques de mayor tamaño, como los observados en el cauce actual, indican que la depositación de estos sedimentos ocurrió en un ambiente relativamente estable (Figura 7). Entre $2,65 \mathrm{~m}$ y $3,25 \mathrm{~m}$ se destaca un abrupto incremento en los valores de limo grueso, con valores que llegan a superar el $50 \%$, los que coinciden con la presencia de material arqueológico en este perfil. Entre 1,65 m y 1,95 m se observa un nuevo incremento en las arenas medias y finas. Si bien los valores de arena gruesa en este nivel también se incrementan, no llegan a ser significativos. Entre estos depósitos finos se intercalan, mayormente en la parte basal de la secuencia, escasas gravas redondeadas desprendidas de las laderas conformadas por sedimentitas neógenas muy friables, sobre las cuales se apoya la terraza. Los bloques neógenos también se encuentran en menor medida en niveles con material arqueológico; si bien es posible que estos se hayan deslizado de las laderas del mismo material, podrían formar parte también de las estructuras arqueológicas observadas. Una situación particular es la del perfil VVP002, el cual presenta una discordancia erosiva entre 1,60 $\mathrm{m}$ y 1,65 $\mathrm{m}$ por debajo de la superficie de la terraza, que corresponde a un paleocauce y representa la única evidencia, aunque de carácter muy localizado, de discontinuidades del registro.

\section{El Testigo TLC y sus resultados sedimentológicos y polínicos}

La secuencia del TLC ofrece una visión sumamente rica desde donde ilustrar los cambios en el paisaje a través de la vegetación. Brinda además, a partir de su estudio sedimentológico, una primera aproximación a lo sucedido con la morfodinámica del área y, particularmente, con los sedimentos en el fondo del valle. En la Figura 8 se 


\section{VVP001}

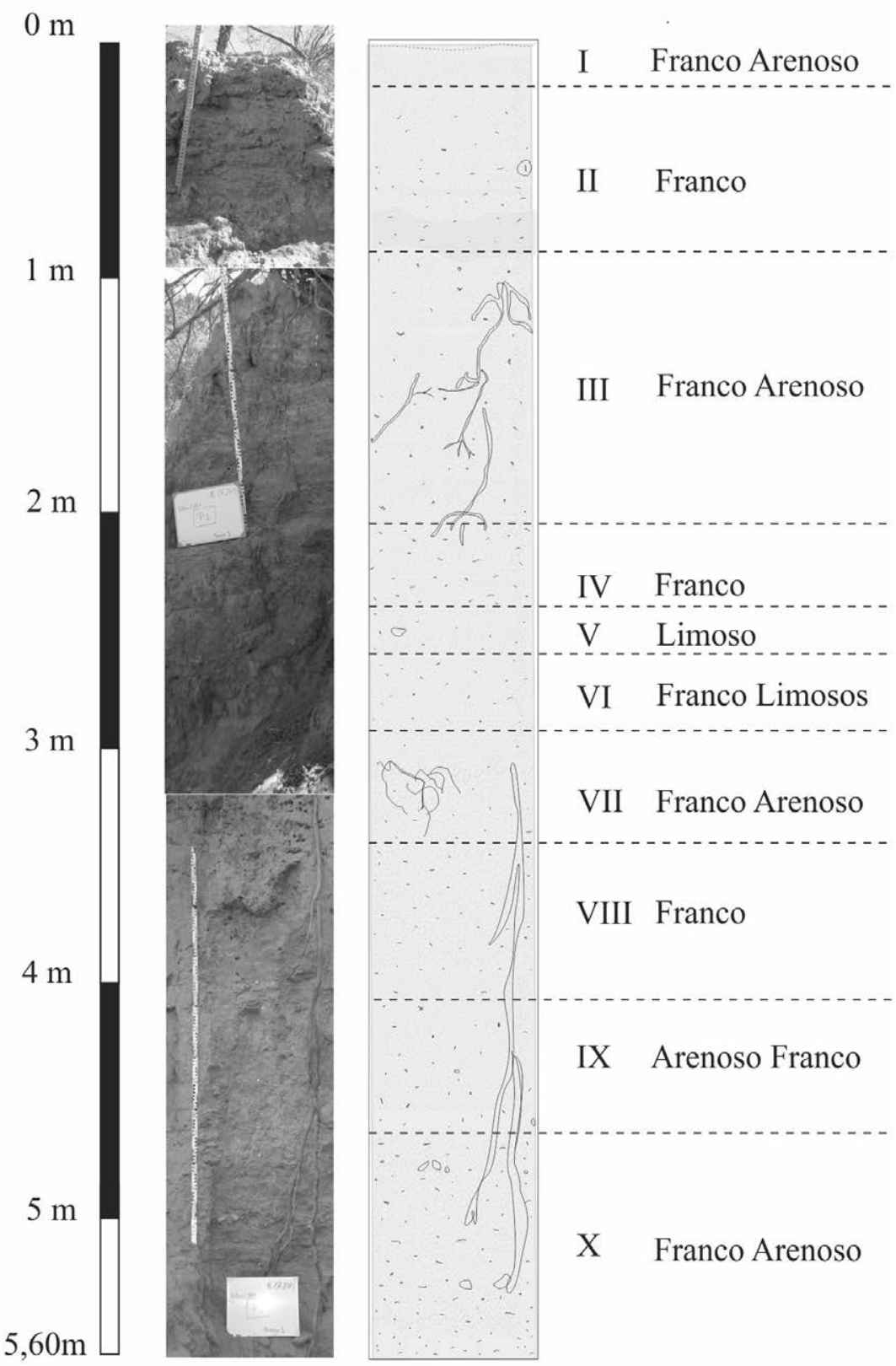

Figura 7. Villa Vil Perfil oo1, sedimentos y composición textural.

observan los sedimentos del TLC. El tratamiento de la edad-profundidad de estos sedimentos muestra un incremento del orden del 100\% en la tasa de acumulación de sedimentos detectada a partir del período Formativo. Esto orientó los trabajos geoarqueológicos que detallamos antes, ampliando las posibilidades de estudio sobre la dinámica de ocupación del valle a escala regional.

Se identificaron un total de 29 tipos polínicos presentes actualmente en el valle. El polen fósil contenido en el TLC mostró una sucesión de seis zonas en las que puede observarse una fluctuación entre estepa arbustiva y estepa herbácea puneña a lo largo 

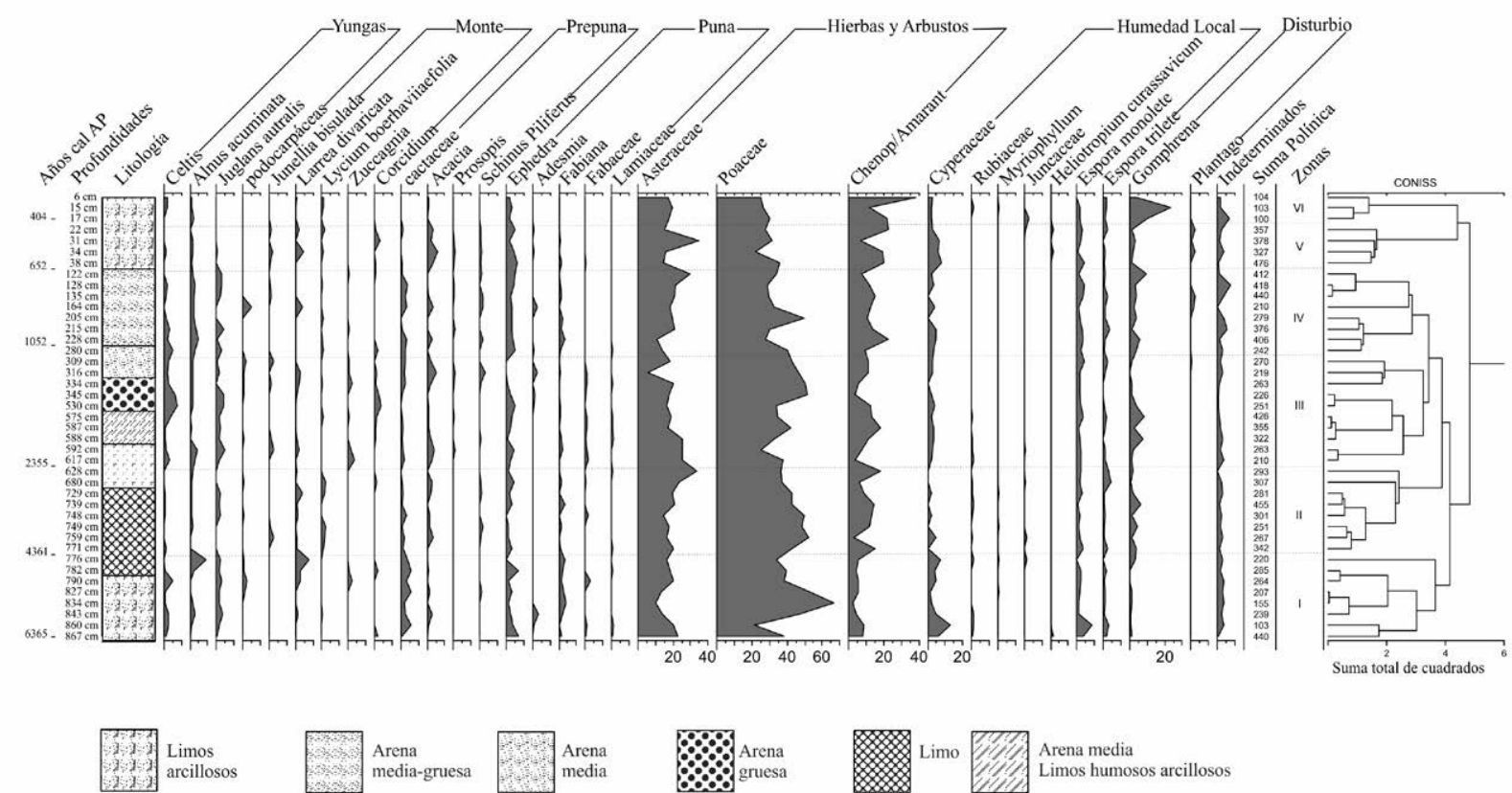

Figura 8. Sedimentos y diagrama polínico de Laguna Cotagua (síntesis). En el mismo se observan edades radiocarbónicas y edades interpoladas calculadas con Tilia 2.0.41.

de toda la secuencia. En la Figura 8 se sintetiza lo observado. A continuación detallamos los resultados de este análisis.

Zona I. Corresponde al lapso entre 6365 y 4361 años cal AP (edad interpolada). Los sedimentos son de tipo arena gruesa con intercalaciones de arena media y limos arcillosos ricos en humus. Los indicadores de humedad local alcanzan sus picos máximos aquí (25\%) con Cyperaceae (15\%), esporas triletes (10\%) y monoletes (10\%). La vegetación local, representada en Poaceae (65\%), es la más elevada también aquí en relación a toda la secuencia, acompañada por elementos extra regionales de Yungas (15\%) (Celtis, Junglans y Podocarpaceae). De igual modo, las Poaceae alcanzan en esta zona sus mayores picos de representación, mostrando un momento de mayor humedad en la secuencia local con aportes de Yungas.

Zona II. Representa lo sucedido entre 4361 y 2355 años cal AP (edades interpoladas). Dominan las arenas medias y limos arcillosos ricos en humus. Los elementos más representados en la zona anterior, vegetación de Yungas (extra regional) y poaceas (local), disminuyen levemente en este momento, alcanzando máximos de 9\% y 50\% respectivamente. Los indicadores de humedad local alcanzan un $10 \%$, mientras que se incrementan notablemente los elementos de Puna (40\%).

Zona III. Las edades interpoladas ubican esta zona entre 2355 y 1052 años cal AP (edades interpoladas). Los sedimentos son una intercalación de limos, limos arcillosos, arenas medias y gruesas, además se inicia un incremento en la tasa de sedimentación. Cronológicamente es coincidente con lo que se conoce para el área como período Formativo y con las primeras evidencias de ocupación aldeana en el valle. Los elementos de Puna decrecen hasta $10 \%$ y se incrementan los indicadores de disturbio superando el $10 \%$. En tanto los indicadores de humedad local y la vegetación extra regional tienen fluctuaciones que varían en porcentajes de 15\% (Cyperaceae, esporas triletes y monoletes) y $10 \%$ (Celtis, Alnus acuminata y Juglans australis) respectivamente. 
Zona IV. Comprende el periodo desde 1052 a 652 años cal AP (edades interpoladas). Los sedimentos están compuestos por arenas medias-gruesas y limos. Los elementos de humedad local fluctúan en un 15\%. En tanto los elementos de Puna tienen un incremento al final de esta zona, alcanzando el 35\%. Los indicadores de disturbio comienzan a incrementarse desde aquí al final de la secuencia, llegando a tener valores del $10 \%$. La vegetación extra regional de Yungas alcanza valores máximos de $15 \%$.

Zona $V$. Comprende el periodo entre 652 a 404 años cal AP (edades interpoladas). Se trata de sedimentos conformados casi exclusivamente por limos. Los elementos de Monte (20\%), Prepuna (20\%) y Puna (35\%) se incrementan. Los indicadores de humedad local disminuyen levemente al final de esta zona (hasta 10\%), mientras que los indicadores de disturbio se mantienen en los mismos porcentajes que en la zona anterior.

Zona VI. Comprende los últimos 404 años cal AP representados en la columna sedimentaria y está compuesta de limos arcillosos. Los elementos de la vegetación local, regional y extra local se mantienen constantes en relación a la zona V. Este período se distingue del anterior por los notables incrementos en los indicadores de disturbio, como Gomphrena (25\%) y de algunos tipos polínicos como Chenopodiaceae y Amaranthaceae (40\%).

\section{Discusión}

Los resultados obtenidos de los diferentes estudios pueden, en conjunto, mostrarnos una imagen sobre cómo fue moldeándose el paisaje en El Bolsón durante los últimos milenos. La integración de los datos geoarqueológicos y palinológicos muestra diferentes escalas temporales y espaciales en las que los cambios del paisaje pueden ser interpretados. Por un lado, una escala temporal más amplia desde la cual podemos hablar de momentos de cambio y estabilidad en el paisaje desde el Holoceno medio a la actualidad y, por otro, desde una escala más acotada, entendida en los términos en los que esos procesos pudieron ser vividos, percibidos, entendidos e integrados a la dinámica de ocupación del valle por parte de las poblaciones que, desde tiempos prehispánicos, lo habitaron, creando y transformando el paisaje.

Los resultados palinológicos de Laguna Cotagua muestran fluctuaciones a lo largo de la secuencia, sin evidenciar cambios abruptos en cuanto a la vegetación. En el Holoceno medio (6365 años cal AP Zona I y 2355 años cal AP en la zona II) habría tenido lugar el momento de mayor humedad en el valle, lo que coincide, relativamente, con otras investigaciones en la región, como el valle de Chaschuil (Brunotte, Garleff y Stingl, 1988; Garleff, Schäbitz, Stingl y Veit, 1991) y, para momentos más tardíos, con Antofagasta de la Sierra (Grana, 2012) y Puna de Jujuy (Oxman, 2015). La arqueología, por su parte, no ha producido aún datos contextuales sobre las ocupaciones humanas para las fechas más tempranas representadas en los testigos sedimentarios analizados. Una distribución de puntas de proyectil tipológicamente asignables al período Arcaico en los tramos medios y superiores (vegas de altura) de las quebradas tributarias en el sector norte alcanza para indicar que en estos momentos se estaban ocupando distintos microambientes del valle (Quesada et al., 2013). La ausencia de sitios con cronologías del Holoceno medio en el fondo de valle puede ser explicada, entonces, por la dinámica geomorfológica descrita en este trabajo: las eventuales ocupaciones estarían sepultadas por la agradación y/o destruidas por la incisión. Los avances en la reconstrucción de la evolución del paisaje local pueden brindar las pautas que permitan desarrollar prospecciones orientadas a los sitios donde los registros arqueológicos sobre esos periodos pudieron haberse preservado. 
Entre 2355 años cal AP y 1052 años cal AP las condiciones climáticas continúan siendo más húmedas que las actuales. En este marco se dan las primeras ocupaciones del Formativo y el desarrollo de los primeros paisajes aldeanos agropastoriles (Korstanje, 2005; Maloberti, 2012). La sedimentología del TLC y los indicadores de disturbio indican el inicio de una progresiva antropización del paisaje. En trabajos previos de este equipo se señaló que era probable que la mayor disponibilidad de humedad efectiva en la altura, debida a mayores precipitaciones y menor evapotranspiración, haya sido uno de los factores que favorecieron un mayor número de instalaciones agrícolas durante el Formativo en el sector norte de la cuenca (Korstanje, 2005; Kulemeyer et al., 2013). Sin embargo, los estudios geomorfológicos abordados aquí brindaron una nueva imagen sobre las formas de ocupación del fondo de valle. En las terrazas de Villa Vil se evidencia que los sectores más bajos, al sur del área de estudio, estuvieron también ocupados en estos momentos. Si bien, como se mencionó arriba, por la naturaleza del registro no pueden caracterizarse en detalle estos sitios, la abundancia de materiales arqueológicos y la dispersión temporal de las dataciones muestra al fondo de valle como un lugar de ocupación sino continua al menos recurrente. En este contexto debemos considerar que la fecha más temprana de ocupación para el valle (2187 años cal AP) proviene de un contexto arqueológico en el perfil VVP006. Nueva información sobre los sedimentos finos de los sectores central y norte, aún en proceso de análisis, reforzarían la hipótesis de una ocupación temprana del fondo de valle en todos los sectores.

Desde 1052 a 652 años cal AP hay un aumento en las condiciones de aridez y los indicadores de disturbio se incrementan, acentuándose hasta la actualidad, lo cual se correlaciona con diversos antecedentes en la región (Brunotte et al., 1988; Grana, 2012; Oxman, 2015). Los sedimentos de terraza reflejan condiciones de escurrimiento reducido, en cauces vegetados (humedales) y el aporte de materiales coluviales y aluviales, producto de la erosión de las vertientes (Kulemeyer et al., 2013). Prospecciones en las vegas altas y el fondo de valle muestran en estos momentos el inicio del avance de dunas provenientes de la Puna. Gale y Haworth (2005) señalan que estos cambios pueden estar vinculados a los cambios en el uso de la tierra. Considerando la fecha radiocarbónica más reciente obtenida de las terrazas fluviales de Villa Vil de 734 años cal AP (VVP009) se infiere que hasta ese momento los depósitos se encontraban en formación y que luego de esto comenzó la incisión que formó las terrazas.

Esto puede estar corroborado por la información arqueológica de este lapso temporal, que corresponde, aproximadamente, al período de Desarrollos Regionales en la secuencia arqueológica regional. A nivel local, el rasgo diagnóstico más conspicuo es la cerámica estilo Belén y en menor medida estilo Santa María. Durante este período por primera vez hay registro de ocupación en superficie en todos los sectores y microambientes del valle. En el sector norte se hallaron materiales de este período en sitios del fondo de valle, como Vaca Vizcana, mientras que en las quebradas subsidiarias se verifica una continuidad o reocupación de aldeas agropastoriles del periodo Formativo (Quesada y Maloberti, 2015). Recientemente, en las vegas de altura se recuperó cerámica Belén y Santa María, lo que estaría evidenciando una ocupación tardía más amplia a la esperada. En el sector central se registraron sitios del periodo de Desarrollos Regionales como La Angostura en los bordes de la amplia vega que forma allí el río El Bolsón en el fondo de valle (Puente, 2010; Quiroga y Korstanje, 2007). Por último, en el sector sur se hallaron cerámicas características de este lapso temporal en los techos de las terrazas fluviales, sobre las mismas superficies que ocupan las viviendas actuales. Esto parece confirmar que la agradación en el fondo de valle culmina en algún momento de este periodo.

El último tramo de la secuencia palinológica, desde 404 años cal AP, refleja un incremento de las condiciones de aridez. Los indicadores de disturbio se incrementan 
también hacia el final de este periodo. Durante el mismo, que se corresponde con el colonial temprano o Hispano-indígena en la secuencia regional, se asume que hay un marcado vuelco de las lógicas económicas locales desde una producción campesina agropastoril a una ganadería extensiva de animales de origen europeo. En tal contexto, el valle de El Bolsón y otros valles altos y oasis puneños, son transformados en "potreros" en el marco de formas productivas de las estancias (Quiroga, 2003).

\section{Conclusiones}

Los resultados obtenidos a través de esta investigación muestran a El Bolsón como un espacio en continua transformación. Por un lado, la secuencia paleoambiental muestra una relativa estabilidad en cuanto a la distribución de la vegetación, aunque con momentos de mayor presencia de especies extra regionales y/o indicadoras de disturbio antrópico. Los depósitos, en cambio, muestran un incremento en la tasa de acumulación de sedimentos en los fondos de valle desde por lo menos 1352 años cal AP, que podría correlacionarse con un direccional proceso de erosión en las vertientes del valle. A nivel geomorfológico pueden notarse los cambios más marcados, sobre todo a partir de $c a .1000$ años AP cuando se verifica, por un lado, un significativo fenómeno de incisión de las terrazas fluviales y, por otro lado, el avance de arenas eólicas proveniente de la Puna, que forma dunas en las cabeceras del valle en el sector norte. Este último proceso será estudiado en mayor detalle en investigaciones futuras.

En el marco de tales transformaciones, la arqueología muestra que la ocupación humana fue, en términos generales, relativamente continua. No puede notarse un hiato de ocupación como el que fue propuesto para otros valles próximos como el de Chaschuil, aunque allí se asoció las causas a un evento volcánico de gran magnitud (Ratto et al., 2013). Quizá la excepción a lo dicho sea el breve período Inka, para el cual no se ha obtenido ningún registro a la fecha. No obstante, y en base a la presencia de elementos diagnósticos en regiones aledañas, se sospecha que tal ausencia se debe más a un problema de muestreo que a una desocupación real del valle. Con todo, tal continuidad no puede esconder las adaptaciones locales en el marco de transformaciones del paisaje. Las tendencias generales señaladas anteriormente a escala regional o del valle, tuvieron efectos distintos cuando se los observa a una escala menor, la de los contextos locales que conforman los mundos de la vida en los cuales se articulaban las estrategias campesinas. Así, al tiempo que en el área estudiada se producía un fenómeno de erosión de laderas en los sectores altos (proceso que podría ser visto como de degradación ambiental), en los sectores de fondo de valle se conformaban espacios propicios para la ocupación humana. Sobre ello es elocuente la notable secuencia de reocupación de las superficies de los depósitos fluviales de Villa Vil entre 2593 y 734 años cal AP. Lo mismo puede decirse en relación al proceso de incisión que luego de 734 años cal AP destruyó aquellos espacios campesinos, lo cual significó la persistencia o reocupación de los paisajes agrícolas del Formativo en los sectores estables de los tramos medios de las quebradas tributarias o la colonización agrícola de los nuevos depósitos de abanicos aluviales en el fondo de valle durante el PDR.

Si bien la escala local otorga un rol creativo a la acción humana, al mostrar elecciones concretas en el marco de un abanico de posibilidades ambientales, conserva aún una causalidad direccional. Las estrategias campesinas serían adaptaciones o respuestas al ambiente que aparece, entonces, como una variable independiente. Sin embargo, podría ser el caso que hayan sido las mismas elecciones culturales los agentes causales de al menos algunas transformaciones ambientales. Se señala en particular la posibilidad de que el incremento de la práctica del pastoreo, principalmente en los sectores elevados del valle pudiera ser la causa del incremento de la tasa de 
acumulación de sedimento en el fondo de valle a partir de aproximadamente el 1340 cal AP (Kulemeyer et al., 2013).

Tales situaciones, que deberán ser estudiadas con mayor detalle, señalan por un lado la importancia de un enfoque multiescalar sensible a los efectos locales de las tendencias ambientales y al mismo tiempo la necesidad de abordar los procesos ambientales y culturales de manera integrada como intentamos hacer en este trabajo.

\section{Agradecimientos}

Los datos que aquí se presentan son el resumen de trabajos iniciados hace un par de años, realizados gracias al financiamiento de CONICET, ANCyPT y CIUNT. El conteo polínico y los análisis sobre sedimentos fueron posibles gracias a la colaboración del Laboratorio de Suelos del Museo Pasquini López de la provincia de Jujuy y al personal del Laboratorio de Palinología de la Facultad de Ciencias Agrarias de la Universidad Nacional de Jujuy. Queremos agradecer especialmente a los evaluadores de este trabajo, sus observaciones y comentarios han enriquecido notablemente el texto. 


\section{Q Referencias citadas}

" Baied, C. y Wheeler J. (1993). Evolution of High Andean Puna Ecosystems: Environment, Climate, and Culture Change over the Last 12,00o Years in the Central Andes. Mountain Research and Development, 13(2), 145-156.

» Bronk Ramsey, C. (2009). Bayesian analysis of radiocarbon dates. Radiocarbon, 51(1), 337-360.

» Brunotte, E., Garleff, K. y Stingl, H. (1988). Anthropogene Beeinflussung der Morphodynamik im Bolsón von Fiambalá / Nordwestargentinien. Abhandlungen der Preußischen Akademie der Wissenschaften, Philosophisch-Historische Klasse, (3)41, 307-327.

"Cabrera, A. L. (1976). Regiones fitogeográficas argentinas. En W. F. Kugler (Ed.), Enciclopedia Argentina de Agricultura y Jardinería (Tomo 2, Fascículo 1, pp. 1-85). Buenos Aires: ACME.

»Cruz, A. (2012). Los cambios del paisaje a través de la vegetación en el Valle del Bolsón (Belén, Provincia de Catamarca). Estudio paleopalinológico. (Tesis de Licenciatura inédita), Universidad Nacional de Jujuy, Argentina.

» Erdtman, G. (1960). The acetolysis method. Svensk Botanisk Tidskrift, 54, 561-564.

" Faegri, K. e Iversen, J. (1989). Textbook of Pollen Analysis (4ta edición (Eds.) K. Faegri, P. E. Kaland y K. Kriwisky). Chichester: JohnWiley \& Sons.

»Fauqué L. y Tchilinguirian P. (2002). Villa Vil rockslide, Catamarca province, Argentina. En S. G. Evans y J. V. DeGraff (Eds.), Catastrophic Landslides: Effects, Occurrence, and Mechanisms (Vol. 15, pp. 303-324). Boulder: Geological Society of America.

" Flantua, S., Hooghiemstra, H., Vuille, M., Behling, H., Carson, J. F., Gosling, W. D., Hoyos, I., Ledru, M. P., Montoya, E., Mayle, F., Maldonado, A., Rull, V., Tonello, M. S., Whitney, B. S. y González-Arango, C. (2015). Climate variability and human impact on the environment in South America during the last 2000 years: synthesis and perspectives. Climate Past Discuss, 11, 3475-3565.

"Gale, S. y Haworth, R. J. (2005). Catchment-wide soil loss from pre-agricultural times to the present: transport- and supply-limitation of erosion. Geomorphology, 68, 314-333.

» Garleff, K., Schäbitz, F., Stingl, H. y Veit, H. (1991). Jungquartärea Landschaftsentwicklung und Klimageschichte beiderseits der Ariden Diagonale Siidamerikas. Bawzberger Geograpliisclze Schrijten, 11, 359-394.

"Grana, L. (2012). Arqueología y Paleoambiente: Dinámica cultural y cambio ambiental en sociedades complejas de la Puna meridional argentina. (Tesis Doctoral inédita), Universidad de Buenos Aires, Argentina.

» Gray, J. (1965). Palynological techniques. En B. Kummel y D. Raup (Eds.), Handbook of Paleontological techniques (pp. 471-587). San Francisco: W. H. Freeman and Co.

» Grimm, E. (2004). Tilia y TGView 2.o.2. Springfield: Illinois State Museum.

"Heusser, C. (1971). Pollen and Spores of Chile: Modern Types of Pteridophyta, Gymnospermae and Angiospermae. Tucson: The University of Arizona Press.

" Hogg, A., Hua, Q., Blackwell, P., Niu, M., Buck, C., Guilderson, T., Heaton, T., Palmer, J., Reimer, P., Reimer, R., Turney, C. y Zimmerman, S. (2013). SHCal 13 Southern Hemisphere Calibration, 0-50,000 Years cal BP. Radiocarbon, 55(4), 1889-1903.

"Irurzun, J. (1978). Contribución al conocimiento del clima de la Provincia de Catamarca. Geografía de Catamarca. Sociedad Argentina de Estudio Geográficos, 5, 43-81. 
» Korstanje, M. A. (2005). La organización del trabajo en torno a la producción de alimentos en sociedades formativas (Provincia de Catamarca, República Argentina). (Tesis Doctoral inédita), Universidad Nacional de Tucumán, Argentina.

» Korstanje, M. A. (2007). Territorios Campesinos: Producción, Circulación y Consumo en los Valles Altos. En A. Nielsen, M. C. Rivolta, V. Seldes, M. Vázquez y P. Mercolli (Eds.), Producción y Circulación Prehispánicas de Bienes en el Sur Andino (pp. 191-223). Córdoba: Brujas.

"Kulemeyer, J. J. (2005). Holozane Landschaftsentwicklungim Einzugsgebiet des Rio Yavi (Jujuy/Argentina). (Tesis Doctoral inédita), Universitat Bayreuth, Alemania.

» Kulemeyer, J. J. y Lupo, L. C. (1998). Evolución del paisaje bajo influencia antrópica durante el Holoceno Superior en la cuenca del río Yavi, Borde oriental de la Puna. Jujuy, Argentina. Bamberger Geographische Schriften, 15, 256-268.

» Kulemeyer, J. J., Lupo, L. C., Madozzo Jaén, C., Cruz, A., Cuenya, P., Maloberti, M., Cortés, G. y Korstanje, M. A. (2013). Desarrollo del Paisaje Holoceno en la Cuenca de El Bolsón, Catamarca: gente y ambiente en procesos de cambio y estabilidad. Diálogo Andino, 41, 25-44.

» Lupo, L. C. (1998). Estudio sobre la lluvia polínica actual y la evolución del paisaje a través de la vegetación durante el Holoceno en la cuenca del río Yavi. Borde Oriental de la Puna, Noroeste argentino. (Tesis Doctoral inédita), Universidad de Bamberg, Alemania.

» Lupo, L. C. y Echenique, M. (2001). Reconstrucción arqueopalinológica de los diversos momentos de ocupación del yacimiento Formativo Moralito. Jujuy, Noroeste Argentino. Ameghiniana, 8, 125-130.

» Lupo, L. C., Kulemeyer, J. J., Sánchez, A. C., Pereira, E. A. y Cortés, G. (2016). Los archivos paleoambientales en el Borde Oriental de la Puna y sus respuestas a los cambios naturales y antrópicos durante el Holoceno. Noroeste argentino. Estudios Sociales del NOA, 16, 39-68.

" Madozzo Jaen, M.C. (2009). Micromamíferos del Holoceno tardío: taxonomía, tafonomía y reconstrucción paleoambiental. (Tesis de Licenciatura inédita), Universidad Nacional de Tucumán, Argentina.

» Maloberti, M. (2012). El paisaje campesino visto desde emplazamientos agrícolas particulares: Alto Juan Pablo (Departamento Belén, Catamarca). (Tesis de Licenciatura inédita), Universidad Nacional de Tucumán, Argentina.

» Markgraf, V. (1985). Paleoenvironmental history of the last 10,000 years in Northwestern Argentina. Zentralblattfür Geologie und Paläontologie, 11/12, 1739-1749.

» Markgraf, V. y D’ Antoni, H. (1978). Pollen Flora of Argentina: Modern Spore and Pollen Types of Pteridophyta, Gymnospermae, and Angiospermae. Tucson: University of Arizona Press.

"Meléndez, A. S. (2015). Ocupaciones humanas y paleoambiente en la cuenca inferior del río El Bolsón (Dpto. Belén, Catamarca). Una aproximación desde la geoarqueología. La Zaranda de Ideas, 13(2), 107-118.

" Meléndez, A. S. y Sentinelli, N. (2017). Dinámica ambiental y materiales arqueológicos de las terrazas fluviales del río El Bolsón (Dpto. Belén, Catamarca). Mundo de Antes, 11, 99-127.

» Morlans, M. (1995). Regiones naturales de Catamarca. Provincias geológicas y provincias fitogeográficas. Revista de Ciencia y Técnica, II(2), 1-42.

» Olivera, D., Tchilinguirian, P. y De Aguirre, M. J. (2006). Cultural and environmental evolution in the Meridional Sector of the Puna of Atacama during the Holocene. En H. Yacobaccio y D. Olivera (Eds.), Change in the Andes: Origins of Social Complexity, Pastoralism and Agriculture (pp. 7-15). Oxford: BAR International Series, Archaeopress. 
» Olivera, D., Tchilinguirian, P. y Grana, L. (2004). Paleoambiente y arqueología en el Holoceno de la Puna Catamarqueña: archivos ambientales, escalas de análisis y registro arqueológico. Relaciones de la Sociedad Argentina de Antropología, XXIX, 229-247.

»Oxman, B. I. (2015). Paleoambiente y sociedad durante el Holoceno en la Puna de Jujuy: Un abordaje palinológico. (Tesis Doctoral inédita), Universidad de Buenos Aires, Argentina.

» Oxman, B., Yacobaccio, H. D., Tchilinguirian P. y Lupo, L. C. (2016). Nuevos análisis polínicos y sus implicancias arqueológicas durante la Pequeña Edad de Hielo en la Puna. Estudios Sociales del NOA, 16, 13-38.

»Peña Monné J. L. y Sampietro Vattuone, M. M. (2016). La secuencia paleoambiental holocena de la vertiente oriental de Loma Pelada (Valle de Tafí, Noroeste Argentino): cambios climáticos y acción humana. En M. M. Sampietro Vattuone y J. L. Peña Monné (Eds.), Geoarqueología de los Valles Calchaquíes (pp. 23-64). San Miguel de Tucumán: Universidad Nacional de Tucumán.

»Puente, V. (2010). Prácticas de Producción Alfarera en el Valle del Bolsón (Belén, Catamarca). Materias Primas y Modos de Hacer CA. 900 - 1600 D.C. (Tesis Doctoral inédita), Universidad de Buenos Aires, Argentina.

»Quesada, M. y Maloberti, M. (2015). Continuidades en la construcción del paisaje agrario entre los Períodos Formativo y de Desarrollos Regionales en el oeste de Catamarca (siglos I a XV). En P. Cruz, R. Joffre y T. H. Winkel (Eds.), Racionalidades Campesinas en los Andes del Sur. Reflexiones sobre el Cultivo de la Quinoa y otros Vegetales Andinos (pp. 140-165). San Salvador de Jujuy: EdiUnju.

»Quesada, M. N., Moreno, E. A. y Meléndez, A. S. (2013). Territorios en el tiempo. Las vegas de altura del Valle de El Bolsón (Dpto. Belén, Catamarca) y su articulación a las economías locales. Trabajo presentado en las XI Jornadas Regionales de Investigación en Humanidades y Ciencias Sociales, San Salvador de Jujuy, Argentina.

»Quiroga, L. (2003). El Valle del Bolsón (siglos XVII-XVIII). La formación de un paisaje rural. Anales. Nueva Época, 6, 301-327.

»Quiroga, L. (2007). Arquitectura de la vivienda prehispánica y colonial. Una perspectiva comparativa en el área valliserrana del Noroeste Argentino. En A. M. Aranda Bernal (Coord.), Actas del Congreso Internacional de Arquitectura Vernácula (pp. 71-77). Sevilla: Universidad Pablo de Olavide.

»Quiroga, L. y Korstanje, M. A. (2007). Arqueología del Campesinado en el Valle del Bolsón. Producción y Residencia como Líneas de Análisis para una Escala de Larga Duración. En M. J. Figuerero Torres y A. Izeta (Eds.), El Uso de SIG en la Arqueología Sudamericana (pp. 101-124). Oxford: BAR International Series, Archaeopress.

» Ratto, N., Montero, M. C., Hongn, F. y Valero Garcés, B. (2013). La historia ambiental de las sociedades productivas del oeste tinogasteño (Catamarca), siglos I al XVI. En N. Ratto (Comp.), Delineando Prácticas de la Gente del Pasado: los Procesos Socio-Históricos del Oeste Catamarqueño (pp. 45-65). Buenos Aires: Sociedad Argentina de Antropología.

»Schäbitz, F., Lupo, L. C., Kulemeyer, J. A. y Kulemeyer J. J. (2001). Variaciones en la vegetación, el clima y la presencia humana en los últimos 15.000 años en el borde oriental de la Puna, provincias de Jujuy y Salta, noroeste argentino. Asociación Paleontológica Argentina. Publicación Especial, 8, 155-162.

» Schittek, K., Kock, S. T., Lücke, A., Ohlendorf, C., Kulemeyer, J. J., Lupo, L.C. y Schäbitz, F. (2016). A high-altitude peatland record of environmental changes in the NW Argentine Andes (24ㅇ) over the last 2,100 years. Climate of the Past, 12(5), 1165-1180.

» Turner, J. C. (1973). Descripción geológica. Laguna Blanca, hoja 11d Escala: 1: 200.000. Buenos Aires: Dirección Nacional de Geología y Minería. 
» Yacobaccio, H. D. y Morales, M. (2005). Mid-Holocene and human occupation of the Puna (Susques, Argentina). Quaternary International, 132, 4-14.

» Yacobaccio, H. D. y Morales, M. (2011). Ambientes pleistocenos y ocupación humana temprana en la Puna argentina. Boletín de Arqueología PUCP, 15, 337-356.

» Yacobaccio, H. D., Morales, M. R., Solá, P., Samec, C. T., Hoguin, R. y Oxman, B. I. (2013). Mid-Holocene Occupation in the Dry Puna in NW Argentina: Evidence from the Hornillos 2 Rockshelter. Quaternary International, 307, 38-49. 